\title{
The Distinction Between Pastoral and Elegy - the Interpretation of the Causes for the Tragic Ending of Border Town
}

\author{
Jiashu Dai", Weijuan Wang, Xiangyi Li \\ School of Liberal Arts, Jimei University, Xiamen 361021, Fujian, China \\ Email: dh292801@hotmail.com
}

\begin{abstract}
Pastoral or elegy? Comedy or tragedy? The novel that can cause such entanglement and confusion in modern Chinese literature is none other than Border Town. Whether it is the author's "counter-attack" of the original creative style of Xiangxi theme, the frustration of readers' aesthetic expectations, or the "violation" of the popular aesthetic habits, all things have a reason. In the final analysis, there are at least three reasons for this intense and long-lasting discussion and persistent suspicion: the influence of the female view formed by the author's life experience on the work; the lack and dislocation of the heroine's view of love in the work; high-level requirements for aesthetics in literary works.
\end{abstract}

Keywords: pastoral, elegy, tragedy, Border Town

\section{Introduction}

Border Town has been published for 82 years since 1934. It is Shen Congwen's most representative work reflecting Xiangxi. It was selected as one of the top 100 Chinese novels in the 20th century and ranked second, second only to Lu Xun's Scream. ${ }^{[1]}$ The ending of Border Town is a difficult problem left by the writer to the literary world.

Even though it is a problem, it is a controversy caused by the great contrast between the tone of the work and the ending. As far as the tone and style of the work are concerned, it exudes an air of pastoralism, but its ending is separated from the main melody of the pastoral, and an elegy of "death" (an interlude) is played. Two distinct melodies coexist in the work. Here, the "interlude" not only takes the lead, but also becomes the main theme as a counter attack.

The novel is devoted to the author's "humanity" aesthetic ideals and pursuits. Pastoral originally meant to refer to the ballads sung by the shepherd, but also refers to literary works based on pastoral life. But its essence is to highlight and praise the natural and fresh rural life in contrast with the degraded, intriguing, and intriguing urban life. Because of the various elements of literary creation and aesthetic orientation, the attributes of "pastoral" in Border Town have been realized, which makes people feel confused. Liu Xiwei: Border Town is "an idyllic masterpiece". ${ }^{[2]}$ Xia Zhiqing commented that Border Town is a representative work that "can be called pastoral type" and has a "pastoral atmosphere". ${ }^{[3]}$ Yang Yi believes that Shen Congwen's "the pastoral sentiment of the novel not only has the leisurely and relaxed atmosphere of Tao Yuanming, but also has the poignant and mysterious style of Qu Yuan's Nine Songs. ${ }^{[4]}$

However, the love between Cui Cui and Nuo Song, which readers pay most attention to in Border Town, ends in an elegy. Cui Cui's grandfather also passed away at the end of the work, leaving Cui Cui alone. The bleak atmosphere suddenly condenses at the end of the work, playing the elegy of "death".

Elegy is a poem written to the dead. This also means the failure of Cui Cui's love and misfortune for the rest of her life. For stubborn Chinese readers, the ending of the novel seriously exceeds their aesthetic expectations. One of the characteristics of Shen Congwen's novels is usually: the novels that reflect Xiangxi and the city must be like a chasm; the former is pastoral style; the latter is satire and criticism. The former is beautified, the latter is ugly. Loves and hates are clear, don't tangle or trouble. But here, the love between Cui Cui and Nuo Song could not end up as a family, but end in tragedy? Secondly. Shen Congwen once explained the motivation for creating Border Town, "What I want to express is a form of life, a beautiful, healthy and non-human life form." ${ }^{[5]}$ This shows that there is a huge gap and dislocation between the original intention of the creation and the end of the work. The "abrupt" change at the end of the song must have a cause, and the author believes that there are at least three reasons.

\section{Reasons for the great contrast between the tone of the work and the ending}

\subsection{The influence of the female view formed by life experience on the work}

The key women in Shen Congwen's life gave him a new understanding of life and love. These women gave him a new understanding of life and human nature and life, and formed migration. 
The first is Ding Ling. Although there are various versions and sequels of Shen Congwen and Ding Ling's grievances, his relationship with Ding Ling is a past tense when he created Border Town. Even so, the impact is lifetime. Since getting to know Ding Ling in early 1925, the relationship between Shen Congwen and Hu Yepin and Ding Ling has entered a delicate relationship, both as friends and as brothers and sisters. In 1931, Hu was killed frequently, and Shen Congwen took the risk to escort Ding Ling mother and son back to her hometown of Changde, Hunan, so that the date of returning to school was delayed and the job was lost. In 1932, Shen Congwen went to visit Ding Ling. Ding Ling had lived with Feng Da at that time. Shen Congwen thought that Ding Ling and Feng Da were not appropriate, but Ding Ling disagreed.

When he first entered the city, Shen Congwen had a strong sense of frustration and regarded sex as a refuge. At this time, Shen Congwen imagined Ding Ling more sex than love. Before that, he had written erotic works such as Old Dreams, Huangjun's Diary, Long Summer, and The Man Who Became a Man for the First Time. Before he entered Zhang Zhaohe's life, he had more fantasies about the experience of both sexes than personal experience. Acquainted with Zhang Zhaohe, Shen Congwen began his first love in the true sense. The qualitative change of Ding Ling's emotions made her realize that she must think deeply about both sexes. This inevitably affected Shen Congwen's creation of Border Town. The emotional entanglement between him and Ding Ling not only embodies the contradiction between ideals and reality, but also causes him to lack confidence in a better future. Therefore, in the creation of Border Town, the vaguely revealed sense of tragedy is found at the end of the work. freed.

The second place is Zhang Zhaohe. Shen Congwen fell in love with Zhang Zhaohe for the first time. Her beautiful and elegant temperament made Shen Congwen obsessed and began a long journey of pursuit. Zhang Zhaohe had no feeling for Shen Congwen at first, but under Shen Congwen's unyielding pursuit, Zhang Zhaohe was finally shaken. She said, "I have reached such a level and I still think about others everywhere. Although I don't think he is cute, but his heart is always pitiful and respectable. That's right." ${ }^{[6]}$ In September 1933, they entered the palace of marriage. At this time, Shen Congwen began to write Border Town. Cui Cui in Border Town has the shadow of Zhang Zhaohe. For example, Cui Cui's temperament and skin are very similar to the author's wife. At the beginning of the creation of Border Town, it was during the author's wedding honeymoon, just like Cui Cui in Border Town, living in a carefree and trouble-free paradise. What is puzzling is that the ending of Border Town ends with the tragedy of a broken love?

Shen Congwen said in Shui Yun that Border Town is "writing some kind of suppressed dream on paper" and "a bit of emotional backlog. Family life cannot completely neutralize it and consume it. It takes a bit of legend, a kind of painful experience out of coincidence, a tragedy that must have occurred from my "past" responsibility. In other words, a perfect love life cannot adjust my life, but a gentle tone. Writing about love, writing about pastoral songs that are completely opposite to my current life, but very similar to my past emotions, can hope to balance my life." ${ }^{\text {[7] }}$ It can be seen that when the fantasy of romantic love in my heart moves toward real marriage, the author I start to feel tired mentally, this is a new spiritual crisis. At this time, another woman, Gao Qingzi, who made Shen Congwen's heart again, appeared in his world at the right time.

Gao Qingzi was the tutor of Xiong Xiling, the first prime minister of the Republic of China. The two had a good impression when they first met. When we met again, Gao Qingzi deliberately dressed up like the heroine in Shen Congwen's novel The Fourth, and the two began to date after they understood. Although this extramarital affair made him enjoy romantic love again, Shen Congwen did not lose his mind. In the end, he chose marriage and Gao Qingzi also chose to leave him.

The aforementioned Shui Yun was written in 1942, which can be regarded as the author's disclosure of his emotions in the ten years since the creation of Border Town. Whether it is the author's defense of emotional derailment or that a happy and peaceful married life cannot completely consume the passionate energy of the soul, it can be regarded as the result of his excess libido with the help of Border Town. There are some works by Shen Congwen whose creation purpose is not much different from Border Town, such as A Little Scene under the Moon, but the result is comedy rather than tragedy! This shows the uniqueness and exceptionality of Border Town.

Cui Cui is the goddess in the author's literary imagination and the last piece of pure land in Shen Congwen's spiritual world. The goddesses who appeared in his life and real life earlier, without exception, finally stepped off the altar, fading the halo and gorgeous colors sadly. The author does not want Cui Cui to lose her aura once she faces reality. Since the beautiful feelings between the two sexes cannot stay in the heart forever, and the beautiful things do not have a perfect ending, the spiritual idol of Cui Cui can't let it enter the palace of marriage on earth anyway. All he can do is to prevent Cui Cui from repeating his mistakes and quickly find the "stop loss", that is, to block it from the door of marriage. Therefore, the ending of Border Town came to an abrupt end, and it made sense to end with tragedy. 


\subsection{The lack and dislocation of the heroine's view of love in the work}

The environment in which Cui Cui grew up was a kind of purity that was deliberately filtered, and even the composition of her family members was so pure-grandfather and granddaughter. This innocence is a flaw for the young girl who is in love. In the transition of Cui Cui's role (from a girl to a young woman), the absence of young men in their lives is another cause of tragedy. Freud believes that in the process of children's sexual psychological growth, they are the first to meet with opposite-sex parents. Daughters will have affection for their fathers and even dislike their mothers. This is the "Electra complex." ${ }^{[8]}$ If a girl does not successfully transform the "Electra complex" in the process of growing up, it will affect her love, marriage, and even the happiness of her life. The successful transformation of the "Electra complex" into the love of other opposite sexes requires a normal man to exert a subtle influence on her in her living environment, but the role of "grandfather" obviously plays a dislocation effect. When love comes, Cui Cui is at a loss and moves towards tragedy step by step.

Cui Cui and her grandpa depend on each other for life, and her grandpa puts all his paternal love, maternal love and his own love on Cui Cui. Deformed feelings are fermented in this confined and narrow space and allowed to develop.

When Cui Cui was growing up, no one helped her get her normal emotional needs. Although he has always been with her grandfather, her understanding of love has been reduced to two people living together. He couldn't appreciate the shyness of the young girl's sprout, and he couldn't appreciate the subtle emotional changes in love. More often, he just played the role of a supporter. Facing Cui Cui's marriage, all he can do is "deliberately test and inquire" this way. Grandpa never asks Cui Cui directly what she thinks in her mind, and often mistakes her granddaughter's love. The conversation between grandparents and grandchildren is like "a chicken talks with a duck." After encountering the exorcism, Cui Cui subconsciously thought about how to get rid of her dependence on her grandfather, and she was afraid that her grandfather would die. On the other hand, she had expectations for the initial emotional object. The appearance of Nuo Song is an opportunity for Cui Cui's love to transfer smoothly. As long as her grandfather guides her or some men around her influence her, she can make the right choice when facing suitors. However, under the influence of her grandpa, the originally shy girl Cui Cui became more afraid to express her emotions in her heart. Just like before the third Dragon Boat Festival, when Nuo arrived at Cui Cui's home, she implicitly expressed her love for Cui Cui. However, Cui Cui took an escape method. "Originally, because no one ferried them, so they wanted to go ashore to burn the fire, but when her grandfather called out, she didn't go ashore." Nuo was about to leave, she still didn't want to go ashore. She was obviously tempted by the young man in front of her, but pretended not to understand. So Nuo sent couldn't get the exact answer, and finally missed.

\subsection{High-level requirements for aesthetics in literary works}

When commercial novels of the "Mandarin Duck and Butterfly" school appeared in modern times, the concept of "tragedy" in Western aesthetic theory had already had an impact on writers at that time. After that, it was Lu Xun who applied this kind of tragedy consciousness to the creation of novels and achieved great achievements. It is true that in the entire modern literary creation, this kind of tragedy consciousness has been more or less tried to be applied and developed continuously. It can be said that the introduction of the concept of "tragedy" in Western aesthetics into modern Chinese novels brought about a radical change in the creation of Chinese traditional novels, and gained the title of modern novels in the true sense.

As for Border Town created in the 1930s, it should be a kind of self-consciousness to reflect this kind of consciousness.

A review of Shen Congwen's Xiangxi novels reveals that most of his works create a dreamy and poetic realm due to the writer's deliberate aesthetic pursuit. This is a "haven paradise" style that filters out impurities. Most readers have already qualitative and fixed the creative style of Shen Congwen.

In fact, some of Shen Congwen's works that express Xiangxi ended in "tragedy", such as A Hei Xiaoshi $\cdot$ Rain, Three Men and One Woman, Three Three, Gui Sheng and so on. Strictly speaking, this kind of ending is more about the impermanence and uncertainty of life, so the tragic treatment of the ending is usually accidental death or unforeseen disappearance or death from illness, which leads completely to a kind of contingency, fatalism and uncertainty of fate. Without the inevitability of life logic or character logic, the appeal of tragedy is lost. Perhaps this is a dialogue between Shen Congwen, who has been in remote mountainous areas for a long time, and the almost "magical" and "primitive" thinking form of Xiangxi, which can be regarded as a unique way and tool for them to perceive the world. "He doesn't want to prescribe a certain solution to the protagonist's fate. On the one hand, objectively, life has never reserved a certain future with others. The opportunities for success and failure, comedy and tragedy are equal. On the other hand, subjectively, Shen Congwen was also unable to point out the life path he believed in to the hero of the work." 
Yu Qiuyu mentioned in his book The Secret Structure of Great Works that one of the great secrets of great works lies in its non-closure. It is not closed to a certain period of history or certain typicals, but directly to all people; nor is it closed to various "pseudo-solution states", but to allow the huge dilemma to connect to today and the future. The ending of Border Town is like this: Cui Cui's grandfather died in the night rain, and Nuo sent to Taoyuan because of the death of her brother and the marriage arranged by his father, leaving nothing to Cui Cui. Nuo sent "may never come back, maybe tomorrow", Cui Cui lived lonely while waiting. This ending is so similar to A Dream in Red Mansions. This similarity is not a similarity of the picture, but an explanation, an explanation without an ending. This is due to the high level of aesthetic requirements. It is not only the result of the author's pursuit of breakthrough in creative consciousness, but also the result of the reader's search for improvement in aesthetic taste.

Border Town is a peaceful pastoral, but its ending is an elegy. Savor it carefully, and it's both unexpected and reasonable. The reversal of the ending is not the author's intentional work. It is more like an unintentional work, and it is a natural result and the result of ripening. It is not a breakthrough in the author's writing skills, but a double promotion of creative consciousness and aesthetic consciousness.

\section{References}

[1] Top 100 Chinese Novels in the 20th Century. Asia Weekly. 2006-7.

[2] Liu Xiwei, "Border Town" and "Eight Horses". Literature Quarterly. 1935; 2(3).

[3] Xia Zhiqing. History of Modern Chinese Novels. Hong Kong: Union Press; 1979.

[4] Yang Yi. History of Modern Chinese Novels (Volume 2). Beijing: People's Literature Publishing House; 1993.

[5] Shen Congwen. The preface of Selected Works of Congwen Novels. in Collected Works of Shen Congwen. Guangzhou: Huacheng Publishing House; 1984.

[6] Shen Huchu. Congwen Jiashu. Shanghai: Shanghai Far East Publishers; 1999.

[7] Shen Congwen. Congwen Autobiography. Shanghai: Shanghai First Publishing House; 1934.

[8] Freud. A General Introduction to Psychoanalysis. Beijing: The Commercial Press; 1986.

[9] Ling Yu. From Border Town to the World. Changsha: Yuelu Press; 2006. 